\title{
Critical Water Geographies: From Histories to Affect
}

\author{
Daanish Mustafa ${ }^{1, *}$ and Sarah J. Halvorson ${ }^{2}$ \\ 1 Department of Geography, King's College London, London WC2B 4BG, UK \\ 2 Department of Geography, W.A. Franke College of Forestry and Conservation, University of Montana, \\ Missoula, MT 59812, USA; sarah.halvorson@mso.umt.edu \\ * Correspondence: daanish.mustafa@kcl.ac.uk
}

Received: 9 July 2020; Accepted: 13 July 2020; Published: 15 July 2020

check for

\begin{abstract}
Water resource geography has undergone a considerable transformation since its original moorings in engineering and the pure sciences. As this Special Issue demonstrates, many intellectual and practical gains are being made through a politicized practice of water scholarship. This work by geographers integrates a critical social scientific perspective on agency, power relations, method and most importantly the affective/emotional aspects of water with profound familiarity and expertise across sub-disciplines and regions. Here, the 'critical' aspects of water resource geography imply anti-positivist epistemologies pressed into the service of contributing to social justice and liberation from water-related political and material struggles. The five papers making up this Special Issue address these substantive and theoretical concerns across South and West Asia, Sub-Saharan Africa and North America.
\end{abstract}

Keywords: critical geography; social-hydrological systems; methodological pluralism; access; water affect; scale; relations of power; social justice

\author{
ma.alūm hameñ sab qais miyā $\tilde{n} k \bar{a}$ qissa bhī \\ sab ek se haĩ̃, ye rā̃̃jhā bhī ye 'insha' bhī \\ farhād bhī jo ik nahr sī khod ke laayā hai \\ sab maayā hai \\ We know Qais and all of his tales \\ They're all the same, whither Ranjha or Insha's tales \\ What Farhad divined in his canal \\ It's all an illusion-it's all water
}

\section{Introduction}

The stanza we feature at the beginning of this essay by Ibn-e-Insha (1927-1978), a Pakistani poet, identifies three heroes-Qais, Farhad and Ranjha-from immortal romantic legends in Arabic, Farsi and Punjabi cultures. To our minds, it illustrates how water is interpellated with emotions and affect, since time immemorial in all major civilizations and cultures. The contributions in this Special Issue not only feature a revisiting of memory encased in history and text, but also lived emotions, anxieties and traumas mediated by spatially and temporally scaled hydro-social relations. If social power relations make up the spine that binds critical water studies across topical, geographical and temporal terrains, the contributions in this Special Issue provide new and refreshing ways of recognizing, problematizing and ultimately resisting those power relations. From methodological pluralism, to historical hydro-social imaginaries, to hegemonic knowledge value systems, to tensions between those systems and lived local scale worlds of emotion, memory, sociability and solidarity, the tropes explored in this Special Issue help us think about ways through which unequal power relations can be materially and discursively demystified and undermined. 
We argue that there are many intellectual and practical gains from the integration of the "critical" with the hydrological. The gains are demonstrated in the work of geographers who integrate a critical social scientific perspective on agency, power relations, and social dynamics with profound familiarity and expertise with specific areas of water science, engineering, and/or other water-related disciplines. We identify this intellectual practice as critical water resource geography, grounded in a deeply held view that socio-hydrological systems and landscapes are produced through colonial histories, social stratifications, racist and gendered ideologies as well as an abundance of interactions between water, geology, biophysical elements, topography, and changing climate. Critical water resource geography emerges through scrutiny and work to make all of these interactions decipherable.

Water is critical to life, but not just bare life. Beyond a resource for economic development and accumulation, it is also imbricated in questions of esthetics (Zenko and Menga, 2019); well-being (Turley and Caretta, 2020); history, identity, sociability, social justice (Rusca and Di Baldassarre, 2019); empire and gender (Halvorson and James, 2020); and nation building (Aijaz and Akhter, 2020). The contributions in this Special Issue speak to the question of emotions, as well as methodological questions of affect, in addition to the histories and geographies of exclusion and heroic water engineering. Following Blomley [1] (2006), we do maintain that the word critical in critical geography implies anti-positivist epistemologies pressed into the service of social justice, undermining oppressive power structures and promoting solidarity not only among humans but between humans and the non-human world. We are happy to report that we may have gone considerable distance towards setting a critical water geography agenda in this Special Issue, but, more than anything, we have managed to place emotional geographies of water as a central item on the agenda for critical water geographies. Equally, we are also mindful of the silences that demand a place on the critical water geography. Silences that we have not been able to break include human/non-human hydro-social relations and deeper explorations of the hydro-social in art, literature, culture, and landscape design.

This collection of papers aims to chart some new ground in putting forward evocative explanatory frameworks. It contains five papers tackling a diversity of issues and scalar approaches. We are not fans of tokenism, but we note with pride that of the ten authors and co-authors in this Special Issue six are women, four of them as lead authors. It is therefore no coincidence, perhaps, that the role of emotions and affect, a central tenet of feminist geographical approaches, which would include Feminist Political Ecology (Sultana, 2020) [2], features as prominently in this Special Issue.

\section{Contributions}

To start with the fundamental self-image of critical water geography as foundationally anti-positivist, Rusca and Di Baldassarre (2019) [3], in this issue, caution us against confusing the ontological commitment to reductionism, generalizability, universality and objectivity with the use of quantitative methods. They draw on a case study that investigates class differentiated access to water in Lilongwe, Malawi, using Geographical Information Systems (GIS) to understand the spatiality and temporality of water access in the low-income neighborhoods of the city. Using the case studied, they rightly argue that critical water researchers, hydrologists and engineers talking past each other does not serve any emancipatory or progressive purpose. They propose that quantitative geographies are not necessarily tied to absolute notions of space and time and linear casualties, but are often consonant with the realization within hydrological sciences that there can be multiple working hypotheses, and that modelling involves unavoidable subjectivity. They further propose that natural and social scientists do not occupy different universes but are rather on a spectrum, where power relations, cultural beliefs and cognitive biases that influence people's engagement with hydrological regimes can indeed be captured by mixed qualitative and quantitative methods. They successfully contest, through their case study, the correlation between "epistemological and methodological differences and disciplinary incompatibility" (p. 7). Rusca and Di Baldassarre (2019) issue a clarion call to not abandon the potential good with the positivist bad of what has gone before through quantitative methods, but instead recognize the limitations of different methodological and 
epistemological positions, and take advantage of the complementarities between the two. Theirs is an important intervention that the critical geographers would do well to heed, if they are to remain pragmatically relevant to the project of helping create more just water geographies.

From the relevance of the historic intellectual trope of quantitative methods to actual historical texts on British water, sanitation and health practices in 18th and 19th century India, Halvorson and Wescoat (2020) [4] remind us of how colonial imaginaries cast a long shadow over contemporary urban water and sanitation geographies in South Asia. Reading the British Army Medical Department's Statistical, Sanitary and Medical Reports (Sanitary Reports) from the 1860s, they provide a rich account of how military-state-society relations diverged from civilian public health programs. They highlight how India was constructed through these accounts as a land of peril with "lurking evils" and unpredictable "choleric attacks", from which the sons of the empire-in the military-had to be protected. Halvorson and Wescoat (2020), in particular elucidate how the relatively higher incidence of venereal diseases among the European as compared to the Indian troops led to isolating the Indian women sex workers in oppressive "lock hospitals", to protect the British soldiers. These attempts at enforcing the purity of behavior mimicked attempts at defending against the choleric disease offensive by spatially isolating the cantonments from the apparently hygienically corrupt and unsanitary "native" habitations. The strategies of stigmatization, isolation, surveillance and enclavement that Halvorson and Wescoat (2020) recount, take on urgent relevance in the contemporary context of an ongoing COVID-19 pandemic, in Pakistan in particular. Civilians are being excluded from the best funded and equipped military hospitals, throughout the country, even though normally they do cater to the public. However, more than that, the heavily militarized Pakistani administration is increasingly engaging in an exercise of blaming the public for the rampant spread of COVID-19, with one provincial minister declaring the public to be ignoramuses, largely to deflect heavy criticism of the government's own bungled response to the pandemic. The critical geographical analysis of historic water and sanitation in colonial India gives us an insight into the contemporary geographies of health and the discursive constructions of the "ignorant public".

Even beyond the COVID-19 pandemic, the emergence of the gated community phenomena also closely mimics 18th century techniques of spatial enclaves in cantonments and separate water and sanitation infrastructure from the wider society, at the expense of the urban poor (Mustafa, et al., 2017) [5]. The political toxicity of contemporary colonial attitudes is compounded by the real consequences of the loss of life in the current pandemic, and fragmented geographies of water access in the global south. Critical historical water geography points us towards antecedents of the present-day conundrums.

Taking a comparable historical approach, but linking it more explicitly to contemporary water debates in the Indus basin, Aijaz and Akhter (2020) [6] demonstrate that colonial and post-colonial states always tried to depoliticize water. The attempts at depoliticization by invoking techno-scientific authority, however, always led to repoliticization through organized pushback and struggle by the subaltern public and water users. The authors mobilize the concept of waterscape to engage with scalar and temporal politics of water in the Indus. From large dam construction in the name of "national survival" to persecution of religious minorities over sharing of drinking water utensils, they argue that these seemingly disparate events and issues have important knowledge/value structures underlying them, that provide remarkable stability across temporal and spatial scales. Aijaz and Akhter (2020) offer a periodization of water development in the Indus during two imperial phases (1849-1886 and 1886-1947) and two post-colonial phases (1947-1991 and 1991-present). Assembling a convincing narrative arc, they establish that the state has always privileged technocratic engineering perspectives to deny the political, cultural and economic valence of water, especially to the differentially vulnerable by gender and class. Water, they say, has a "moral ecology" that the state goes to great lengths to deny, primarily through systemic under-valuing of place-based values, knowledge systems and uses of water. Through their critical historical analysis of Indus water geographies, Aijaz and Akhter (2020) remind us of the urgency of connecting scalar and cultural dimensions of water politics-a foundational enterprise for critical water geographies, indeed. 
The theme of disempowerment at the hands of technocracy evoked above by Aijaz and Akhter (2020), takes center stage in Turley and Caretta's (2020) [7] account of household water security in the context of hydraulic fracturing in West Virginia, Appalachia in the United States. Weaving their account around the concept of water security as time and place specific and constituting the three essential dimensions of water access, quality and affect, i.e., emotional, cultural and subjective experience of water, Turley and Caretta (2020) focus in on how drinking water quality concerns around hydro-fracking in West Virginia intersect with water affect. Through their case study, they ably document how the uneven power relationship between the residents and the drilling companies that are also responsible for water quality testing, manifests itself in delayed test results, prevarications around causes for arsenic contamination of groundwater, and procedural irregularities in testing, thereby leading to epistemic injustice. The technocratic understandings of water quality risk do not match or address the residents' risk perceptions and their desires for protection from those risks. Framing of water quality risk in technical terms with technical solutions, they argue, constitutes epistemic injustice where knowledge claims with greater power devalue the emotional and subjective anxieties of residents. The critical analyses offered by Turley and Caretta (2020) frame the affective aspects of water, as integral to water security, something that critical water geography research and policy agenda would do well to integrate as well.

Taking the water affect idea to center stage, Zenko and Menga (2019) [8] outline how powerful hydro-social imaginaries led to the degradation of Lake Urmia in Iran, and the consequent incidence of psychological depression, social isolation and intra-community conflict among the people living around the lake. They leverage the concept of hydro-social territory to argue how changes in spaces (re)created through human practices and water flows impact the mental health of the populations. Ever attentive to scalar politics inherent in hydro-social territories they forensically illustrate how the desiccation of Lake Urmia is an outcome of watershed scale water diversions for municipal, agricultural and industrial use, yet the remedy for the consequences of watershed scale (mis)management are sought through local scale regulation and infrastructure development. They also problematize how climate change is blamed by the authorities for what is really a management-driven disaster. Regulatory and infrastructure developments are subsequently undertaken in the immediate surroundings of the shrinking lake in the name of climate change adaptation to address the problem. The global scale trope of climate adaptation in this context is a political canard deployed to governmentalize local hydro-social territory, in the name of efficiency and environmental restoration. The consequences are the further constriction of local people's freedom to manage water, greater social conflict, the emergence of new local hierarchies and the breakdown of social capital. The consequences of lake desiccation affect the local scale; the causes are regional scale and reversible management decisions; yet the solutions and hydro-social imaginaries espoused officially, shift the blame to the international scale actors and the climate change they cause. Zenko and Menga (2019) do not just draw attention to the affective and mental health consequences of produced water scarcity, but also offer a cautionary tale on how seemingly progressive tropes like climate change adaptation can be deployed to perverse ends. Such explorations of the deeply human affects of water, and the problematization of popular environmentally virtuous tropes like climate change, are illustrative of what critical water geography is and should be about.

\section{Conclusions}

Ultimately, hydrologies are deeply humanized. Drainages, watersheds, basins, aquifers are as much social as they are physical. Water scientists and scholars have confirmed that the Earth's most life-supporting hydrological processes are so totally dominated and altered by anthropogenic activities that, at times, the seemingly natural elements even appear as veneer, masking underlying dark truths about the implications of our actions.

As we embark on the Special Issue we recognize and acknowledge that there is a history of critical work addressing water resources (perhaps not necessarily within water resources geography itself) 
and precedents for the type of scholarly work upon which we build and extend with these papers. Taken as a whole, this work makes clear that there is so much left for us as we respond in our diverse ways to an urgency for just and inclusive materialist responses to extreme water insecurities and crises. Critical water geography considers and confirms the dialectical co-production of water processes and social processes. The fact that water is so complex-with variations in rates and velocities and amounts of flooding, ripping, trickling, and cascading through and between everything from economics to emotions-offers many opportunities to interrogate and challenge the norms, values, institutions, and systemic injustices. This Special Issue, we hope, provides a set of templates for how critical water geography might speak to the intellectual challenges that society is facing at the start of the third decade of the 21st century.

Author Contributions: D.M. conceived and led development of the paper; S.J.H. contributed to the writing of the paper. All authors have read and agreed to the published version of the manuscript.

Funding: This research received no external funding.

Acknowledgments: The authors, who also served as the guest-editors of this Special Issue, wish to thank the journal editors, all authors who submitted papers to this Special Issue, and the many referees who contributed to the review and revision processes of the final published papers.

Conflicts of Interest: The authors declare no conflict of interest.

\section{References}

1. Blomley, N. Uncritical critical geography? Prog. Hum. Geogr. 2006, 30, 87-94. [CrossRef]

2. Sultana, F. Politicial ecology I: From margins to center. Prog. Hum. Geogr. 2020. [CrossRef]

3. Rusca, M.; Di Baldassarre, G. Interdisciplinary critical geographies of water: Capturing the mutual shaping of society and hydrological flows. Water 2019, 11, 1973. [CrossRef]

4. Halvorson, S.J.; James, W.J.L. Guarding the sons of empire: Military-State-Society relations in water, sanitation and health programs of mid-19th century India. Water 2020, 12, 429. [CrossRef]

5. Mustafa, D.; Gioli, G.; Karner, M.; Khan, I. Contested Waters: Subnational Scale Water Conflict in Pakistan; USIP: Washington, DC, USA, 2017.

6. Aijaz, A.; Akhter, M. From building dams to fetching water: Scales of politicization in the Indus Basin. Water 2020, 12, 1351. [CrossRef]

7. Turley, B.; Caretta, M.A. Household water security: An analysis of water affect in the context of hydraulic francturing in West Virginia, Appalachia. Water 2020, 12, 147. [CrossRef]

8. Zenko, M.; Menga, F. Linking water scarcity to mental health: Hydro-social interruptions in the Lake Urmia Basin, Iran. Water 2019, 11, 1092. [CrossRef]

(C) 2020 by the authors. Licensee MDPI, Basel, Switzerland. This article is an open access article distributed under the terms and conditions of the Creative Commons Attribution (CC BY) license (http://creativecommons.org/licenses/by/4.0/). 